\title{
Effect of preoperative vaginal cleansing using chlorhexidine antiseptic on post cesarean section infectious morbidity
}

\author{
Tyseer Marzouk*1, Hanan Abd-Elmohdy Emarah², Mai Mostafa Zaitoun ${ }^{3}$ \\ ${ }^{1}$ Woman's Health and Midwifery Nursing Department, Faculty of Nursing, Mansoura University, Egypt \\ ${ }^{2}$ Obstetrics and Gynecological Nursing Department, Faculty of Nursing, Zagazig University, Egypt \\ ${ }^{3}$ Obstetrics and Gynecological Department, Faculty of Medicine, Zagazig University, Egypt
}

Received: January 6, 2019

DOI: $10.5430 / \mathrm{cns} . v 7 \mathrm{n} 1 \mathrm{p} 107$
Accepted: February 19, 2019 Online Published: March 5, 2019

URL: https://doi.org/10.5430/cns.v7n1p107

\begin{abstract}
Objective: This study aims to assess effect of preoperative vaginal cleansing using chlorhexidine antiseptic on post cesarean section infectious morbidity.

Methods: A randomized controlled trial was conducted on a random sample of 178 singleton term pregnant woman assigned for elective cesarean section. A simple random sample was recruited from the operating room of Obstetrics and Gynecology department, Zagazig University Hospitals-Egypt. Participants were randomly assigned either to conventional care group or study group. The conventional care group was exposed to the usual abdominal scrub with Povidone-iodine solution; while the study group subjected to vaginal cleansing using chlorhexidine antiseptic solution in addition to conventional preoperative care. Data were collected using an assessment sheet for demographic and clinical data and checklist for study outcomes.

Results: Post intervention, assessment of the incisional wound revealed lower overall post cesarean section infectious morbidity rate among study group compared to those received conventional care $\left(9.0 \%\right.$ vs. $20.2 \%$ respectively; $\left.\chi^{2}=4.50, p=.034\right)$. Endometritis rate was significantly lower among the study group subjects equated to those of the conventional care group $(2.2 \%$ vs. $10.1 \%$ respectively; $\left.\chi^{2}=4.75, p=.029\right)$, meanwhile febrile morbidity and surgical site infection rates showed non-significant reduction in favor to the study group subjects ( $p=.469$ and .700 respectively).

Conclusions: Preoperative vaginal cleansing using chlorhexidine was an effective practice for reducing post cesarean infection; where overall post cesarean infectious morbidity rate was lower among postpartum mothers subjected to vaginal cleansing compared to those exposed to conventional care alone; supporting the study hypothesis.
\end{abstract}

Key Words: Preoperative vaginal cleansing, Post cesarean section, Infectious morbidity

\section{INTRODUCTION}

Post cesarean section (CS) infectious morbidity is a momentous problem that affects woman health and represents an economic burden. Usually post CS infectious morbidity appears in form of endometritis in $6 \%$ to $27 \%$, febrile morbidity in $5 \%$ to $24 \%$, and infection at the incisional site which occurs in around $2 \%$ to $9 \%$ of post cesarean deliveries. ${ }^{[1]}$ Endometritis occurs 10 times post cesarean deliveries compared

\footnotetext{
*Correspondence: Tyseer Marzouk; Email: tm_fathy@yahoo.com; Address: Woman’s Health and Midwifery Nursing Department, Faculty of Nursing, Mansoura University, Egypt.
} 
to post vaginal births. It can be progressed to cause pelvic abscess, peritonitis, or even septicemia; which is of a great concern. $^{[2]}$

Broad spectrum prophylactic antibiotics prior CS deliveries, has been used as a standard practice. Despite that postoperative infectious morbidity still a serious complication after cesarean deliveries. ${ }^{[3]}$ Even if maternal death post CS infection happens in only 6 per 100,000 CS deliveries, its complications are seriously affect the maternal health. These complications may cause longer hospital stay and sometimes hospital readmission, which in turn increase the economic burden. ${ }^{[4]}$

Post cesarean infectious morbidity is caused by ascending the causative bacteria from the vagina and cervical canal; through hematogenous spread, to infect edges of the incised uterus. ${ }^{[5,6]}$ Presence of the causative bacteria in the vagina is known to cause resistance against antibiotic therapy. So, even after receiving preoperative prophylactic antibiotics the vaginal lumen is found to be colonized with antibiotic-resistant bacteria and the rate of post cesarean infections remains a problem. ${ }^{[7,8]}$

Cleansing the vagina before operations is not a new research issue. During the early 1970 s, vaginal cleansing was applied before abdominal hysterectomy, and it has been proved to reduce count of vaginal bacteria and decline the rate of post-operative infection. ${ }^{[9]}$ Later on, researchers evaluated whether or not prior CS cleansing using antiseptics can decrease post cesarean infection. Antiseptics were used in different types (e.g., povidone iodine, metronidazole, and chlorhexidine), different forms (e.g., solutions or wipes), and different methods; such as vaginal cleansing or skin scrub. ${ }^{[10-13]}$

A systematic review was proven that vaginal cleansing using chlorhexidine is fairly safe, not expensive, and easy to be used. ${ }^{[14]}$ The investigators of that review suggested more well-designed randomized clinical trials for evaluating that safe simple valuable procedure. This inspired authors of the current study to assess effect of preoperative vaginal cleansing using chlorhexidine antiseptic on post cesarean section infectious morbidity.

\subsection{Significance of the study}

Overall post cesarean infectious morbidity affects $24.4 \%$ of Egyptian population, with an incidence of $13.2 \%$ with endometritis; in a hospital-based study. ${ }^{[15]}$ Given that evidence, finding a safe simple practice with good efficacy on reducing post-cesarean infectious morbidity is of utmost importance for the nursing and medical staff working at the operating theatre of obstetrics and gynecology department. ${ }^{[16]}$ There- fore, the present study was carried out to assess effect of preoperative vaginal cleansing using chlorhexidine antiseptic on post cesarean section infectious morbidity.

\subsection{Operational definitions}

\subsubsection{Post cesarean section infectious morbidity}

Means occurrence of one or more of three morbidities after cesarean deliveries specifically endometritis, febrile morbidity, and incisional site infection. ${ }^{[17]}$

\subsubsection{Preoperative vaginal cleansing}

It indicates to swab the vaginal lumen from its apex to introitus; using sterile swabs soaked in chlorhexidine solution as an antiseptic agent. Its aim is to get rid of excess vaginal secretions loaded with bacteria. It is done immediately after fixing the Foley's catheter, anesthesia and before skin incision.

\subsection{Aim of the study}

To assess effect of preoperative vaginal cleansing using chlorhexidine antiseptic on post cesarean section infectious morbidity.

\subsection{Hypothesis of the study}

To achieve aim of the present clinical trial, one hypothesis was investigated:

"Pregnant women who are subjected to vaginal cleansing pre elective CS; using chlorhexidine antiseptic solution, report lower rates of overall post CS infectious morbidity compared to those who do not."

\section{SUBJECTS AND METHOD}

\subsection{Research design}

This study was designed as a double-blind randomized controlled trial. Double-blind option was selected to reduce the risk of data bias. In this research design, the assessor of the incisional site was not aware to which group each subject belongs to. As well, the participant women were not aware in which group were located; where preoperative vaginal cleansing was done after anesthesia.

\subsection{Study setting}

The present study was conducted at the operating room (OR) of Obstetrics and Gynecology department-Zagazig University Hospital, Egypt.

\subsection{Sampling}

A simple random sample was recruited to participate in the present study. Each singleton term pregnant woman assigned for elective cesarean section; during the study period from 
beginning of February to end of October 2018, was eligible to participate in the present clinical trial. Unless, had one of the following risk factors which may increase their susceptibility to postpartum infectious morbidity:

(1) Those women with immune compromised status; such as diabetic patients.

(2) Antepartum risk factor for infection; as premature ruptured fetal membranes, anemia, or antepartum hemorrhage.

(3) Those exposed to events known to increase the risk for endometritis during or after the operation. Like, intraoperative bleeding or prolonged operation time.

(4) In addition to those known to have allergy to chlorhexidine antiseptic were also excluded from participation.

\subsubsection{Sample size calculation}

This randomized controlled trial proposed to assess effect of preoperative vaginal cleansing using chlorhexidine antiseptic on post cesarean section infectious morbidity. Based on data from a previous study, ${ }^{[15]}$ considering level of significance $5 \%$, power $80 \%$, type of test is two-sided, and by substitution of the formula: $\mathrm{n}=\left[2\left(Z_{\alpha / 2}+Z_{\beta}\right)^{2} \times p(1-p)\right] /(p 1-p 2)^{2}$, where $\mathrm{n}$ is the sample size required per each group, $\mathrm{p}=$ pooled proportion (proportion of event in $1^{\text {st }}$ group + pro- portion of event in the $2^{\text {nd }}$ group) $/ 2, \mathrm{p} 1-\mathrm{p} 2=$ difference in proportion of events in the two groups, $\mathrm{Z}_{\alpha / 2}$ depends on level of significance, for $5 \%$ it is $1.96, \mathrm{Z}_{\beta}$ depends on the study power; for $80 \%$ it is 0.84 . Therefore, $n=$ $\left[2(1.96+0084)^{2} \times 0.166(1-0.834)\right] /(0.244-0.088)^{2}=$ 89.4. Accordingly, sample size required per each group was 89 women assigned for elective cesarean section.

\subsubsection{Group's allocation}

Each potential participant was allocated into one group by simple randomization method; where randomization was done at an equal ratio (i.e., 1 conventional care: 1 study). Groups' identification was kept in a serially numbered opaque closed envelopes. Half of the envelopes contained letter " $C$ " referring to the conventional care group, while the remaining half contained letter " $\mathrm{S}$ " indicating to study group. Envelopes were opened after confirming eligibility for enrollment and taking informed consents. Subjects of the conventional care group were subjected to conventional preoperative care (i.e., preoperative abdominal skin scrub using povidone iodine solution), while the study group subjects were exposed to the same conventional preoperative care plus preoperative vaginal cleansing using chlorhexidine antiseptic (see Figure 1).

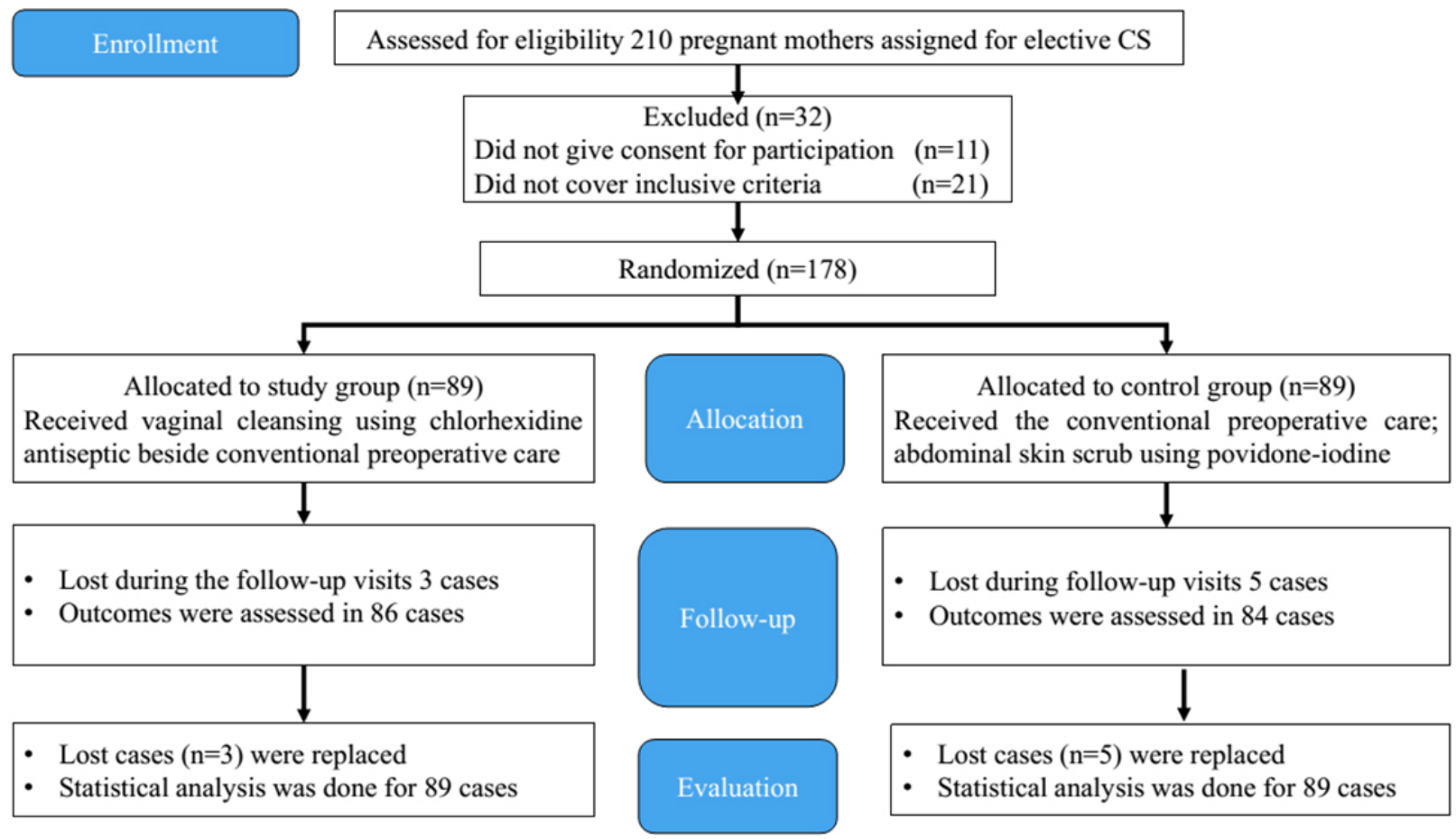

Figure 1. Flow chart of the study groups 


\subsection{Measures of data collection}

\subsubsection{Assessment sheet}

It was designed by the researchers and included demographic characteristics and data related to the participants' clinical profile. Demographic characteristics included maternal age, weight and height with the body mass index value, gestational age at the time of delivery, and parity. Meanwhile, data related to the clinical profile described the CS operation issues; such as its indication, duration, and postoperative hospital stay. These data were completed after reviewing the medical files and attending the operation.

\subsubsection{Checklist of the study outcomes}

It was developed by the researchers and completed at the first postpartum follow-up visit (i.e., at the $10^{\text {th }}$ postpartum day). It was aimed to assess presence or absence of the post CS infectious morbidity: endometritis, febrile morbidity, and incisional site infection. Each morbidity was identified based on criteria given in a previous study by Aschania and coauthors. ${ }^{[16]}$

\section{(1) Endometritis}

It was evident as "Postoperative fever of $38.4^{\circ} \mathrm{C}$ or more, associated with uterine tenderness and offensive smelling lochia requiring administration of broad spectrum intravenous antibiotic".

(2) Postoperative febrile morbidity

It was determined by "Oral temperature of $38^{\circ} \mathrm{C}$ or more after 24 hours of surgery; in absence of clinical causes of infection such as breast engorgement or urinary tract infection".

(3) Incisional site infection

It was identified by presence of erythema or occurrence of abdominal incision disruption, with purulent discharge from incision site that requires antibiotics and wound care.

\subsubsection{Validity of the study measures}

Before data collection, both measures were reviewed by a board of 3 experts in maternity nursing field; to ensure that the questions were unswervingly sent and carried the intended meaning that were designed for.

\subsection{Ethical considerations}

Before starting data collection, approval was taken from the research ethical committee, Faculty of Nursing - Zagazig University to perform the present clinical trial. Each participant was signed an informed consent after receiving explanation about the study aim and nature. All precautions were taken to maintain adequate privacy during the intervention.

\subsection{Research process}

The present clinical trial was completed by passing through three phases: Initial phase, implementation phase, and evaluation of the study outcomes phase.

(1) Initial phase

On arrival to the operating room waiting area, each pregnant woman assigned for elective CS was interviewed. Aim and nature of the study were clarified and informed written consents were signed from the eligible pregnant mothers. At the same phase, the group's allocation was identified.

(2) Implementation phase

In this phase, subjects of the conventional care group were received the conventional preoperative care, while subjects of the study group were subjected to preoperative vaginal cleansing using chlorhexidine antiseptic; in addition to the conventional care.

a. The conventional preoperative care

The conventional preoperative care involves the abdominal skin scrub, which was done according to the following steps: 1) prepare sterile bowel with $30 \mathrm{ml}$ povidone-iodine, 2) after anesthetizing the pregnant woman and inserting the Foley's catheter, abdominal scrub was done by the scrubbed surgeon in form of intense rub of the abdominal incision area using sterile gauze soaked in povidone-iodine solution. It was continued around one to two minutes; to ensure rid of dirt, sweat, and skin bacteria, and 3) the disinfected skin area was wiped with another sterile gauze. Prophylactic intravenous antibiotic was given instantly before skin incision. It is usually 1 gram Cefotaxime (Cefotax, EIPICO, $10^{\text {th }}$ of Ramadan City, Egypt). Thereafter, the cesarean section operation was started as lower segment incision without any intervention over the usual care.

b. Care of the study group

Subjects of the study group were received the conventional care in addition to vaginal cleansing with chlorhexidine solution. After anesthetizing the pregnant woman and inserting the Foley's catheter, vaginal cleansing was done by the scrubbed nurse researcher; who was aware about group allocation and did not involve in incisional site assessment. The vaginal cleansing was done by preparing a sterile bowl with $30 \mathrm{ml}$ chlorhexidine $0.125 \%$ antiseptic solution. In a clockwise manner, the area from the vaginal apex to the introitus was cleansed. The cleansing started with the vaginal apex, followed by the four vaginal fornices (i.e., anterior, posterior, right and left lateral) and ended by the introitus, the vaginal cleansing done in one to two minutes. Thereafter, the conventional care was continued until end of the operation. 
(3) The evaluation phase

The study outcomes (i.e., endometritis, febrile morbidity, and surgical site infection) were evaluated at the $10^{\text {th }}$ day postpartum; where the adhesive tape covering the incision detached and the incision site was exposed for assessment.

\subsection{Strengths and limitations of the study}

Opting double-blind randomized controlled trial design with its least chance for data bias, increase the present study weight. Contrariwise, implementing the intervention at one center may limit possible generalizability of the findings.

\subsection{Statistical analysis}

All statistical analyses were performed using SPSS for windows version 20.0 (SPSS, Chicago, IL). All continuous data were normally distributed and were expressed as mean $\pm \mathrm{SD}$.
Categorical data were expressed in numbers and percentages. The comparisons were determined using Student's $t$-test for two variables with continuous data. Chi-square test was used for comparison of variables with categorical data. Statistical significance was set at $p<.05$.

\section{RESULTS}

\subsection{Basic maternal characteristics and homogeneity}

The basic characteristics of the participant women are presented in Table 1. The mean age of the study group was 25.8 years, while in the conventional care group was 26.7 years. There was no statistical significant differences between both groups concerning maternal age, body mass index, parity, gestational age at delivery, birth weight, indication and duration of the $\mathrm{CS}$, which indicates that both groups were matched and homogeneous.

Table 1. Basic characteristics of the participants by the study groups $(n=178)$

\begin{tabular}{|c|c|c|c|c|}
\hline \multirow{2}{*}{ Variables } & \multirow{2}{*}{$\begin{array}{l}\text { Study group }(\mathbf{n}=\mathbf{8 9}) \\
\text { Mean } \pm \text { SD or } n, \%\end{array}$} & \multirow{2}{*}{$\begin{array}{l}\text { Conventional care group }(n=89) \\
\text { Mean } \pm \text { SD or } n, \%\end{array}$} & \multicolumn{2}{|c|}{ Student's $t$-test } \\
\hline & & & $t$ & $p$ \\
\hline \multicolumn{5}{|l|}{ Mother's age at delivery (years) } \\
\hline Range & $18-34$ & $18-34$ & & \\
\hline Mean $\pm \mathrm{SD}$ & $25.8 \pm 4.9$ & $26.7 \pm 5.2$ & 1.11 & .267 \\
\hline \multicolumn{5}{|l|}{ Parity (n, \%) } \\
\hline Nullipara & $8,9.0 \%$ & $12,13.5 \%$ & & \\
\hline Multipara & $81,91.0 \%$ & $77,86.5 \%$ & $0.90^{*}$ & .342 \\
\hline \multicolumn{5}{|c|}{ Maternal body mass index $\left(\mathrm{kg} / \mathrm{m}^{2}\right)$} \\
\hline Range & $27.0-36.9$ & $27.0-36.7$ & & \\
\hline Mean \pm SD & $31.6 \pm 2.8$ & $31.4 \pm 2.6$ & 0.58 & .565 \\
\hline \multicolumn{5}{|c|}{ Gestational age at delivery (weeks) } \\
\hline Range & $37-40$ & $38-40$ & & \\
\hline Mean $\pm \mathrm{SD}$ & $38.6 \pm 3.1$ & $39.4 \pm 3.5$ & 1.63 & .106 \\
\hline \multicolumn{5}{|l|}{ Baby birth weight (grams) } \\
\hline Range & $2,950-3,600$ & $2,700-3,550$ & & \\
\hline Mean \pm SD & $3,293.0 \pm 199.2$ & $3,242.2 \pm 222.4$ & 1.61 & .110 \\
\hline \multicolumn{5}{|l|}{ Indications of cesarean section } \\
\hline Previous cesarean & $71,79.8 \%$ & $69,77.5 \%$ & & \\
\hline Breach presentation & $8,9.0 \%$ & $7,7.9 \%$ & & \\
\hline Cephalopelvic disproportion & $8,9.0 \%$ & $5,5.6 \%$ & & \\
\hline Transverse lie & $2,2.2 \%$ & $8,9.0 \%$ & $4.39^{*}$ & .223 \\
\hline \multicolumn{5}{|c|}{ Duration of the operation (minutes) } \\
\hline Range & $30-35$ & $28-37$ & & \\
\hline Mean \pm SD & $32.6 \pm 1.6$ & $32.9 \pm 2.7$ & 0.91 & .364 \\
\hline
\end{tabular}

Note. ${ }^{*} \chi^{2}$, Chi square test

3.2 Effect of vaginal cleansing on the study outcomes

As illustrated in Figure 2, a statistical significant reduction in overall post CS infectious morbidity was noticed among

Published by Sciedu Press the study group subjects $(9.0 \%)$ compared to $20.2 \%$ in conventional care group $(p=.034)$. The greater reduction was

Published by Sciedu Press 
observed in the endometritis rate; $2.2 \%$ among the study group subjects versus $10.1 \%$ in those received conventional care $(p=.029)$. Lower non-significant decline was noticed in rates of febrile morbidity $(3.4 \%$ vs. $5.6 \% ; p=.469)$ and surgical site infection (3.4\% vs. $4.5 \% ; p=.700)$ respectively among subjects of the study group and conventional care group as presented in Table 2 .
As shown in Table 3, the mean length of the hospital stay was almost similar (2.0 vs. 2.1 days) respectively in study and conventional care groups; with no statistical significant difference $(p=.628)$. The outpatient clinic visit during the postpartum period did not differ significantly between study and conventional care groups $(5.6 \%$ vs. $12.4 \%$ respectively; $p=.116)$.

Table 2. Frequency of post CS infectious morbidity by the study groups $(\mathrm{n}=178)$

\begin{tabular}{|c|c|c|c|c|c|}
\hline \multirow[t]{2}{*}{ Outcomes } & \multirow{2}{*}{$\begin{array}{l}\text { Study group } \\
(n=89) \\
n, \%\end{array}$} & \multirow{2}{*}{$\begin{array}{l}\text { Conventional care group } \\
(\mathrm{n}=89) \\
\mathrm{n}, \%\end{array}$} & \multirow{2}{*}{ OR $(95 \%$ CI $)$} & \multicolumn{2}{|c|}{ Chi square test } \\
\hline & & & & $\chi^{2}$ & $p$ \\
\hline Overall post CS infectious morbidity & $8,9.0 \%$ & $18,20.2 \%$ & $0.39(0.16-0.95)$ & 4.50 & $.034^{*}$ \\
\hline Endometritis & $2,2.2 \%$ & $9,10.1 \%$ & $0.20(0.04-0.97)$ & 4.75 & $.029^{*}$ \\
\hline Febrile morbidity & $3,3.4 \%$ & $5,5.6 \%$ & $0.59(0.14-2.53)$ & 0.52 & .469 \\
\hline Surgical site infection & $3,3.4 \%$ & $4,4.5 \%$ & $0.74(0.16-3.41)$ & 0.15 & .700 \\
\hline
\end{tabular}

Note. ${ }^{*}$ Means significant

Table 3. The length of hospital stay and frequency of clinic visit by the study groups $(\mathrm{n}=178)$

\begin{tabular}{|c|c|c|c|c|}
\hline \multirow{2}{*}{ Outcome } & \multirow{2}{*}{$\begin{array}{l}\text { Study group }(\mathrm{n}=\mathbf{8 9}) \\
\text { Mean } \pm \text { SD }\end{array}$} & \multirow{2}{*}{$\begin{array}{l}\text { Conventional care group }(n=89) \\
\text { Mean } \pm \text { SD }\end{array}$} & \multicolumn{2}{|c|}{ Student's $t$-test } \\
\hline & & & $t$ & $p$ \\
\hline \multicolumn{5}{|c|}{ Length of hospital stay (days) } \\
\hline Range & $1-3$ & $1-3$ & & \\
\hline Mean $\pm \mathrm{SD}$ & $2.0 \pm 0.9$ & $2.1 \pm 0.7$ & 0.49 & .628 \\
\hline Clinic visit (n, \%) & $5,5.6 \%$ & $11,12.4 \%$ & $2.47^{*}$ & .116 \\
\hline
\end{tabular}

Note. ${ }^{*} \chi^{2}$, Chi square test

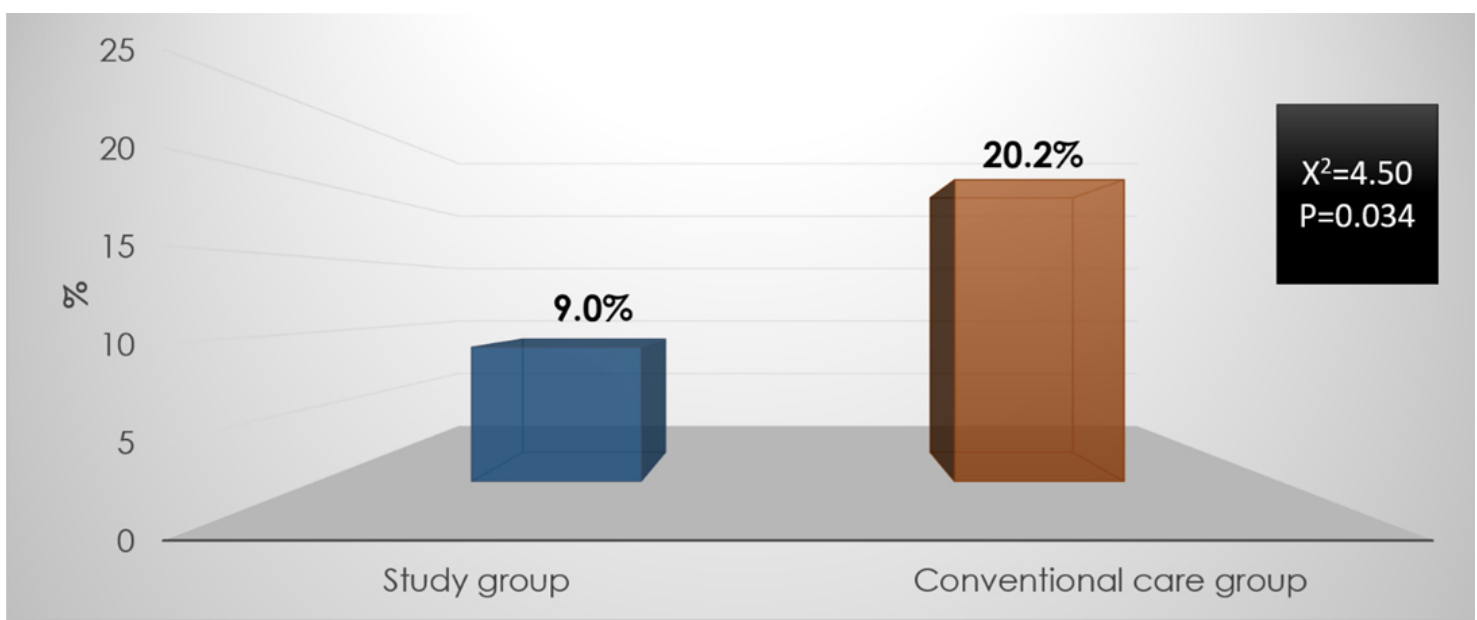

Figure 2. Frequency of the overall post CS infectious morbidity in the study group and conventional care groups

\section{Discussion}

The present study was aimed to assess effect of preoperative vaginal cleansing using chlorhexidine antiseptic on post cesarean section infectious morbidity. This aim was attained through the current study findings. There was statistical significant decrease in overall post CS infectious morbidity among subjects of the study group compared to those of conventional care group. Thus, the study hypothesis "Pregnant women who are subjected to vaginal cleansing pre elective CS; using chlorhexidine antiseptic solution, report lower rates of overall post $\mathrm{CS}$ infectious morbidity compared to those who do not" was accepted. 
Consistent with the present study finding, a randomized controlled trial assessed the effectiveness of preoperative vaginal scrub using chlorhexidine wipes on post CS infectious morbidities in 219 women undergone elective CS at Suez Canal University Hospital, Ismailia city-Egypt. ${ }^{[15]}$ The authors found significant reduction in overall post CS infectious morbidity from $24.4 \%$ in control group to $8.8 \%$ in intervention group. ${ }^{[15]}$ Likewise, Tewfik and coauthors (2015) found significant reduction in overall post CS infectious morbidity in 47 women exposed to vaginal cleansing with chlorhexidine solution before elective CS at Ain Shams University Maternity Hospital, Egypt. ${ }^{[18]}$ The positive effect of chlorhexidine antiseptic on reducing overall infectious morbidity may be attributed to its great antibacterial activity against variety types of aerobic and anaerobic bacteria; involving those associated peripartal infections. In addition to its longer residual effect which make it more advantageous over other antiseptics. ${ }^{[19]}$

Regarding the rate of endometritis, an obvious reduction was evident among subjects of the study group of the current research work. In conformity with the current study finding, an earlier study demonstrated significant reduction in endometritis from $14.3 \%$ to $4.4 \%$; when the influence of preoperative vaginal swabbing using chlorhexidine solution on post CS infectious morbidity was assessed in 232 women in Denmark. ${ }^{[20]}$ In the same line, great significant reduction in rate of endometritis; from $13.2 \%$ in conventional care group to $2.9 \%$ in chlorhexidine vaginal cleansing group, was noticed in Ahmad's and coauthors study. ${ }^{[15]}$

Despite the present study findings showed reduction in wound infection and febrile morbidity in favor to the study group subjects, this reduction was low and insignificant. Similarly, non-significant decline was noticed in rates of febrile morbidity and wound infection among chlorhexidine vaginal cleansing group equated to control group by Ahmed and coauthors. ${ }^{[15]}$ The agreement between findings of the present study and Ahmad et al.'s study may be backed to similar methodologies; where both studies were designed as randomized controlled double-blind, also similarity of the inclusion criteria may explain the agreement between both studies. Contrariwise, Tewfik et al. (2015) found the reduction in febrile morbidity; among vaginal scrub using chlorhexidine group, is statistically significant which may be attributed to the smaller sample size. ${ }^{[18]}$

Concerning length of the hospital stay, there was no statistical significant difference between both groups in the current study. Similarly, Ahmad's and colleagues ${ }^{[15]}$ found non-significant difference between duration of the hospital stay between both groups. Again, this agreement may be related to similarity in methodology and results. Contrariwise, vaginal disinfection before delivery using $0.25 \%$ chlorhexidine results in a significant reduction of the hospital stay between the study groups in two earlier studies; conducted at Egypt and Malawi, to assess influence of vaginal cleansing before delivery on maternal and neonatal morbidity and mortality. ${ }^{[21,22]}$ The non-randomization of the study subjects in both Egyptian and Malawi studies may explain the disagreement between both studies and current study findings.

Previous research evidence denotes that chlorhexidine is well accepted with minimal adverse effects. Wilson et al. (2004) stated that using chlorhexidine vaginal wipes at concentrations less than $1 \%$ is free from adverse skin reactions and it is characterized by being not deactivated by organic materials such as sweat. ${ }^{[23]}$ Given that using chlorhexidine can be an effective, safe, and cost effective practice in reducing post CS infectious morbidity.

\section{Implications in nursing practice}

Chlorhexidine is an effective antiseptic agent against gram positive and gram negative bacteria. Cleansing the vagina is an easy, safe, not time consuming procedure and does not need special experience. It is not deactivated by human body fluids, has a lengthier residual effect, and does not need a postpone time between use and incision equated to other antiseptics. Given that vaginal cleansing using chlorhexidine prior CS can be recommended in nursing practice.

\section{CONCLUSION AND RECOMMENDATIONS}

Based on the existing study results, the tested hypothesis was accepted; where preoperative vaginal cleansing using chlorhexidine was an effective tool in reducing overall post CS infectious morbidity, especially endometritis. Hence, the following can be recommended:

(1) Implementing vaginal cleansing using chlorhexidine antiseptic solution can be recommended as an adjunct to the abdominal skin scrub and prophylactic antibiotic therapy; instantly prior CS for reducing endometrium exposure to bacteria.

(2) Targeting multi centers and evaluating effect of vaginal cleansing on neonatal outcomes can be advised as a future research trials.

\section{CONFlicts of InTEREST Disclosure}

The authors declare they have no conflicts of interest. 


\section{REFERENCES}

[1] Yildirim G, Asicioglu O, Basaran T, et al. Does vaginal preparation with povidone-iodine prior to caesarean delivery reduce the risk of endometritis? A randomized controlled trial. J Matern Fetal Neonatal Med. 2012; 25: 2316-21. PMid:22590998. https: //doi.org/10.3109/14767058.2012.693994

[2] French LM, Smaill FM. Antibiotic regimens for endometritis after delivery. Cochrane Database Syst Rev. 2004; 2: CD001067. https://doi.org/10.1002/14651858.CD001067.pub2

[3] Haas DM, Morgan S, Contreras K. Vaginal preparation with antiseptic solution before cesarean section for preventing postoperative infections. Cochrane Database Syst Rev., 12: CD007892. 2014. https://doi.org/10.1002/14651858.CD007892.pub4

[4] Haas DM, Pazouki F, Smith RR, et al. Vaginal cleansing before caesarean delivery to reduce postoperative infectious morbidity: a randomized, controlled trial. Am J Obstet Gynecol. 2010; 202: 310.e1-6. PMid:20207251. https://doi.org/10.1016/j.ajog. 2010.01 .005

[5] Memon S, Qazi RA, Bibi S, et al. Effect of preoperative vaginal cleansing with an antiseptic solution to reduce post caesarean infectious morbidity. J Pak Med Assoc. 2011; 61: 1179-83. PMid:22355962.

[6] Shrestha S, Shrestha R, Shrestha B, et al. Incidence and Risk Factors of Surgical Site Infection Following Cesarean Section at Dhulikhel Hospital. Kathmandu University Medical Journal. 2014; 46(2): 113-6. https://doi .org/10.3126/kumj . v12i2.13656

[7] Watts DH, Hillier SL, Eschenbach DA. Upper genital tract isolates at delivery as predictors of post-caesarean infections among women receiving antibiotic prophylaxis. Obstet Gynecol. 1991; 77: $287-$ 92. PMid:1988895. https://doi.org/10.1097/00006250-199 102000-00026

[8] Dhanya M, Roger E, Erika O, et al. Antibiotic regimens for postpartum endometritis. Cochrane Database of Systematic Reviews. 2015

[9] Haeri AD, Kloppers LL, Forder AA, et al. Effect of different preoperative vaginal preparations on morbidity of patients undergoing abdominal hysterectomy. S Afr Med J. 1976; 50: 1984-6. PMid:1013853.

[10] Swenson BR, Hedrick TL, Metzger R, et al. Effects of Preoperative Skin Preparation on Postoperative Wound Infection Rates: A Prospective Study of 3 Skin Preparation Protocols. Infect Control Hosp Epidemiol. 2009 October; 30(10): 964-971. PMid:19732018. https://doi.org/10.1086/605926

[11] Anggrahita T, Wardhana A, Sudjatmiko G. Chlorhexidine-alcohol versus povidone-iodine as preoperative skin preparation to prevent surgical site infection: a meta-analysis. Med J Indones. 2017; 26: 54-61. https ://doi.org/10.13181/mji.v26i1.1388

[12] Rodrigues AL, Simoes ML. Incidence of surgical site infection with pre-operative skin preparation using $10 \%$ polyvidone-iodine and
0.5\% chlorhexidine-alcohol. Rev. Col. Bras. Cir. 2013; 40(6): 443448. https : //doi .org/10.1590/S0100-69912013000600004

[13] Tuuli MG, Stout LJ, Martin MJ, et al. A randomized trial comparing skin antiseptic agents at Cesarean delivery. The New England Journal of Medicine. 2016; 1-9.

[14] Lumbiganon P, Thinkhamrop J, Thinkhamrop B, et al. Vaginal chlorhexidine during labor for preventing maternal and neonatal infections (excluding Group B Streptococcal and HIV). Cochrane Database Syst Rev. 2004; 4: CD004070.

[15] Magdy RA, Nisreen KA, Waleed ASA, et al. Chlorhexidine vaginal wipes prior to elective cesarean section: does it reduce infectious morbidity? A randomized trial. The Journal of Maternal-Fetal \& Neonatal Medicine. 2017; 30(12): 1484-1487. PMid:27583685. https://doi.org/10.1080/14767058.2016.1219996

[16] Aschania M, Mirblouk F, Shakiba M, et al. Preoperative vaginal preparation with povidone-iodine on post-caesarean infectious morbidity. J Obstet Gynaecol. 2011; 31: 400-3. PMid:21627422. https://doi.org/10.3109/01443615.2011.568644

[17] Conroy K, Koening A, Yu Y, et al. Infectious Morbidity after Cesarean Delivery: 10 Strategies to Reduce Risk. Obstetrics \& Gynecology. 2012; 5(2): 69-77.

[18] Tewfik H, Ibrahim A, Hanafi S, et al. Preoperative Vaginal Preparation using Povidone Iodine versus Chlorhexidine Solutions in Prevention of Endometritis in Elective Cesarean Section. International Journal of Current Microbiology and Applied Science. 2015; 4 (8): 486-492.

[19] Lim KS, Kam PC. Chlorhexidine pharmacology and clinical applications. Anaesth Intensive Care. 2008; 36: 502-12. PMid:18714617. https://doi .org/10.1177/0310057X0803600404

[20] Frost L, Pedersen M, Seiersen E. Changes in hygienic procedures reduce infection following caesarean section. J Hosp Infect. 1989; 13: 143-8. https : //doi .org/10.1016/0195-6701 (89)90020-0

[21] Taha TE, Biggar R, Broadhead RL, et al. Effect of cleansing the birth canal with antiseptic solution on maternal and newborn morbidity and mortality in Malawi: clinical trial. BMJ. 1997; 315: 21619. PMid:9253269. https : //doi.org/10.1136/bmj . 315.7102 .216

[22] Bakr AF, Karkour T. Effect of pre delivery vaginal antisepsis on maternal and neonatal morbidity and mortality in Egypt. J Woman's Health (Larchmt). 2005; 14: 496-501. PMid:16115003. https: //doi.org/10.1089/jwh.2005.14.496

[23] Wilson C, Gray G, Read JS, et al. Safety and tolerance of different concentrations of chlorhexidine for peripartum vaginal and infant washes. J Acquir Immune Defic Syndr. 2004; 35: 138-43. PMid:14722445. https://doi.org/10.1097/00126334-20040 2010-00006 